\title{
Are doctors risk takers?
}

This article was published in the following Dove Press journal:

Risk Management and Healthcare Policy

17 June 2016

Number of times this article has been viewed

\section{Dvora Pikkel' \\ Yael Sara Pikkel |gal $\left.\right|^{2}$ \\ Adi Sharabi-Nov 3,4 \\ Joseph Pikkel ${ }^{2,5}$}

'Risk Management and Patient Safety Unit, Assuta Medical Center, Ramat Hahayal, Tel Aviv, ${ }^{2}$ Faculty of Medicine, Bar-Ilan University, ${ }^{3}$ Research Wing, Ziv Medical Center, Safed, ${ }^{4} \mathrm{Tel}-\mathrm{Hai}$ Academic College, Upper Galilee, ${ }^{5}$ Department of Ophthalmology, Ziv Medical Center, Safed, Israel
Correspondence: Yael Sara Pikkel lgal Faculty of Medicine, Bar-llan University, 69th Shwedia St Haifa, Safed 34980, Israel Tel +9724504574528

Email yaelpikkeligal@gmail.com
Objective: Risk taking affects human behavior in general and decisions in medicine in particular. We used game theory to assess physicians' risk-taking tendencies.

Methods: Physicians were recruited to the study by advertisement. It was explained that they would receive a sum of money for correct prediction of the flipping of a coin. They could try to sell their opportunity to flip the coin for an amount of money they determined. The sum offered by the participants was considered an indicator of risk taking. A demographic questionnaire assessed age, sex, seniority, and area of specialization of the participants. A multivariate analysis assessed associations between risk-taking behavior and, seniority, and specialization.

Results: Sixty-two physicians participated, 36 males and 26 females, seniority 1-34 years. Of a possible range of $0-10$, the mean score for risk taking was 5.5 - just slightly more than indifference. Negative correlations were found between risk taking and seniority, and between risk taking and age $(\beta=-0.45, P<0.001$ for both). Surgeons and anesthesiologists showed greater risk taking than did other physicians $(\beta=0.69, P<0.05)$; and females less than males, though the latter correlation was not statistically significant.

Conclusion: Understanding the tendency of physicians to risk taking may elucidate their decision-making processes and contribute to understanding of causes of adverse events and to the education of physicians.

Keywords: risk taking, game theory, seniority, surgeons, anesthesiologists

\section{Introduction}

The process of decision making is fascinating and intriguing, especially if the output of the decision has a significant impact. In medicine, we often witness adverse events that result from wrong decision making that was influenced by a wide variety of intraand interpersonal factors. One of these factors is the tendency toward risk taking or the tendency to gamble. Risk taking undoubtedly has disadvantages. On the other hand, it affords the opportunity for change and breakthrough; otherwise, we would probably do too little and progress too slowly. We learn from our successes and our routine behavior, but also from our mistakes and wrong decisions.

Our study is, as much as we know, a first attempt to assess physicians' risk-taking tendencies by using game theory. We assessed doctors' tendency to risk taking without taking a judgmental approach.

Game theory is the study of strategic decision making. It was initially developed to predict economic decision making and behavior by using mathematic algorithms. Game theory is defined as the study of mathematical models of conflict and cooperation between intelligent rational decision makers. ${ }^{1}$ Main applications are to economics, 
political science, and psychology, as well as logic, computer science, and biology. The subject first addressed zero-sum games, such that one player's gain is exactly equal to the other player's net loss. Nowadays, game theory applies to a wide range of behavioral relations, and has developed into an umbrella term for the logical side of decision science, including both humans and nonhumans. Game theory was developed extensively in the 1950s and has since been widely recognized as an important tool in many fields. ${ }^{2}$

By using a well-known game, we measured physicians' tendency to risk taking.

\section{Methods}

Games that are used for predicting behavior can be classified according to the nature of the game and its purpose. We chose a non-cooperative game (there is one player - the physician participating in the study), which is asymmetric (the strategy of the game is independent of other players) and of the "zero-sum" type (choices by players neither increase nor decrease the available resources).

We published a recruitment advertisement in one Medical Center (Ziv Medical Center). Physicians who volunteered to participate were given a short demographic questionnaire, in which they were asked to state their age, sex, seniority, and area of specialization. They then received an explanation of the game.

The game was as follows: the recruited doctor was given a participant card that gave him or her the opportunity to play. It was explained to the participant that the game is flipping a coin and he or she should predict in advance on which side it will fall - "heads" or "tails". The participant was told that if his or her guess was correct, he or she will be given the sum of 100 New Israeli Shekel (NIS) (about 25 USD or EU), and if the guess was wrong then he or she will receive nothing. Then, before entering the room in which the game was expected to be played, the participant was offered to sell his or her participant card for a price that he or she would determine, and told that the examiner could refuse the deal if the price was too high. Participants who wanted to sell stated the price they requested (a few participants were not willing to sell and stated they preferred to play in any case). The examiner recorded their offers and decided whether to buy the ticket or not. Those who claimed too high a price entered the room and played. Those who sold were given the sum they asked for. Each participant underwent the process privately in order to avoid influences of other participants.

The sum offered by the participants was considered an indicator of risk taking. Since chances of winning or losing in a flipping coin game are the same $(50 \%)$ - participants who were willing to sell at a price less than 50 NIS showed low tendency to risk taking - they were actually seducing the examiner to buy and were trying to achieve a sure benefit. Participants who were willing to sell at a price that was higher than 50 NIS expected that the examiner would not buy, and were thus willing to risk a sure profit for the chance of gaining more money.

Figure 1 depicts a table that sums the tendency to risk taking according to the behavior in this game. The study was approved by the local bioethical community of the Ziv Medical Center, Safed, Israel. Written informed participant consent was not required seen as no medical intervention was performed and the study group were staff doctors.

\section{Statistical analysis}

For continuous variables (age and seniority), arithmetic means and standard deviations were calculated. For categorical variables (sex and discipline), number of participants and proportions were calculated. A multiple regression analysis was used to predict risk taking according to medical staff

\begin{tabular}{|c|c|c|c|c|c|c|c|c|c|c|}
\hline \multicolumn{11}{|c|}{ Risk-taking score } \\
\hline 10 & 9 & 8 & 7 & 6 & 5 & 4 & 3 & 2 & 1 & 0 \\
\hline 100 NIS or & 90 & 80 & 70 & 60 & $50 \mathrm{NIS}$ & 40 & 30 & 20 & 10 & 0 \\
\hline $\begin{array}{c}\text { do not want } \\
\text { to sell }\end{array}$ & NIS & NIS & NIS & NIS & & NIS & NIS & NIS & NIS & \\
\hline $\begin{array}{l}\text { Strong risk } \\
\text { taker }\end{array}$ & \multicolumn{4}{|c|}{ Risk taker } & $\begin{array}{l}\text { Indifferent to } \\
\text { risk taking }\end{array}$ & \multicolumn{4}{|c|}{ Risk averter } & $\begin{array}{c}\text { Strong } \\
\text { risk } \\
\text { averter }\end{array}$ \\
\hline
\end{tabular}

Figure I Risk-taking table according to the described and tested game. Abbreviation: NIS, New Israeli Shekel. 
Table I Characteristics of medical staff

\begin{tabular}{llll}
\hline & N & $\%$ & \\
\hline Sex & & & \\
Male & 36 & 58.1 & \\
Female & 26 & 41.9 & \\
Discipline & & & \\
Surgery & 12 & 19.4 & \\
Internal ward & 16 & 25.8 & Range \\
Pediatric & 13 & 21.0 & \\
Anesthesia & 10 & 16.1 & $28-63$ \\
Others & 11 & 17.7 & $1-34$ \\
& Mean & Standard \\
& & deviation & \\
Age (years) & 45.7 & 8.4 & $0-10$ \\
Seniority (years) & 11.8 & 8.0 & \\
Risk-taking score (0-10) & 5.5 & 1.4 & \\
\hline
\end{tabular}

characteristics. A $P$-value of $5 \%$ or less was considered statistically significant. The data were analyzed using the SPSS version 20.0.2 (IBM Corporation, Armonk, NY, USA).

\section{Results}

Sixty-two physicians were recruited, 36 males and 26 females. Characteristics of the physicians are described in Table 1. The range of seniority was 1-34 years. The mean score for risk taking was 5.5 - just slightly more than indifference in risk taking. The range was from 0 to 10 , meaning that some (4) were not willing to gamble at all, while others had a very high urge to gamble, either stating they will play in any case or suggesting to sell for a maximum price of 100 NIS (though the majority were not extreme in either direction).

A multiple regression analysis to assess whether medical staff characteristics can predict risk taking showed statistical significance $\left(R^{2}=0.26, F_{(3,61)}=6.70, P<0.001\right)$. Negative correlations were found between risk taking and seniority, and between risk taking and age (95\% confidence interval $=0.92, P<0.001$ for both). Surgeons and anesthesiologists
Table 2 Multiple regression analysis to predict risk-taking scores by seniority, sex, and discipline of the medical staff

\begin{tabular}{llll}
\hline & B & SE B & 95\% Cl \\
\hline Seniority (years) & -0.08 & 0.20 & $0.92 * * *$ \\
Sex (female) & -0.46 & 0.34 & 0.45 \\
Discipline & 0.69 & 0.35 & $0.83^{*}$ \\
(surgery + anesthesia) & & & \\
$R^{2}$ & & 0.26 & \\
$F_{(3,61)}$ & & $6.70 * * *$ & \\
\hline
\end{tabular}

Notes: $* P<0.05, * * * P<0.001$.

Abbreviations: $\mathrm{Cl}$, confidence interval; $\mathrm{SE}$, standard error.

showed greater risk taking than did other physicians $(95 \%$ confidence interval $=0.83, P<0.05$ ); and females less than males, though the latter correlation was not statistically significant (Table 2).

To eliminate multicollinearity between the variables age and seniority ( $r=0.97, P<0.001$ ), we included in the multiple regression only the seniority variable (Figure 2 ).

A multivariate analysis showed a decrease in risk-taking score, as seniority increased. Surgeons and anesthesiologists tended to gamble more than did physicians of other disciplines (Figure 3). Women showed a lesser tendency to gamble than did men; however, the difference was not statistically significant.

\section{Discussion}

Decision making is crucial in medicine. In many instances, decisions are made in an uncertain environment and with lack of information. Thus, the tendency to risk taking is a factor affecting clinical decision making. ${ }^{3}$

Understanding the tendency of physicians to risk taking may elucidate their decision-making processes. In this study, we used game theory to assess physicians' tendency toward risk taking, according to seniority, age, sex, and medical discipline.

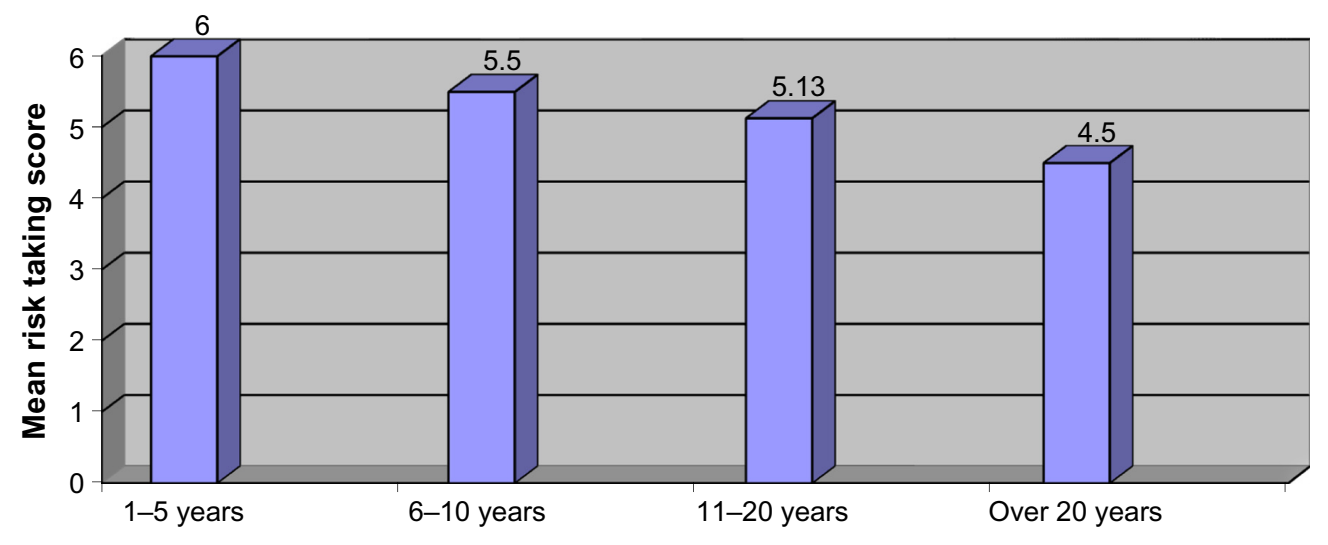

Figure 2 Risk-taking score (mean) by doctors of different seniority. 


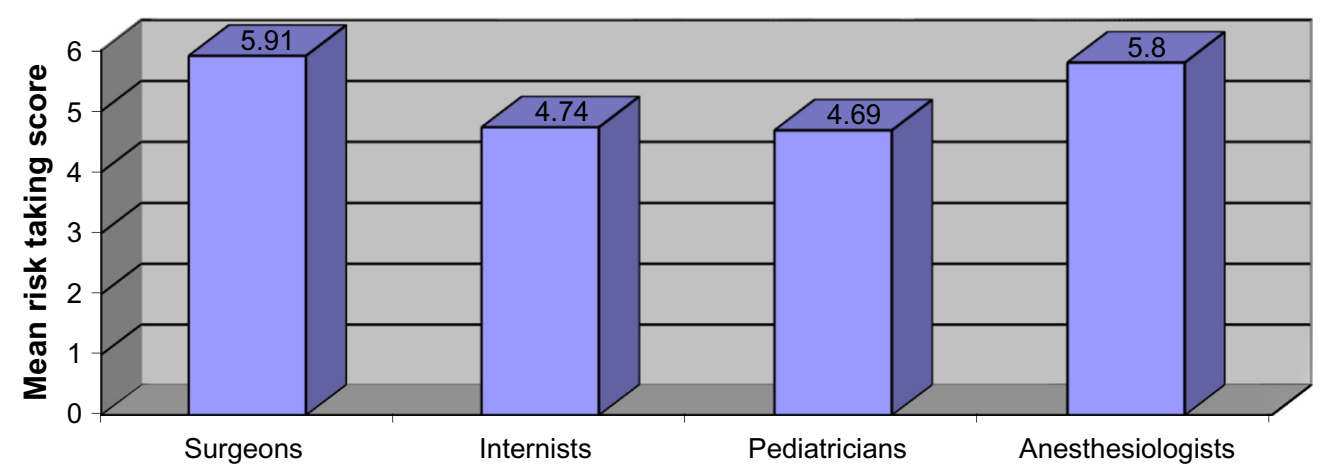

Figure 3 Risk-taking score (mean) by doctors from different disciplines.

Game theory presumes that every person or group of people makes decisions with the interest of gaining maximum benefit from a situation, and that decision making is a purely rational process. Though we assume that physicians are not $100 \%$ rational in their decision making, especially in situations of stress, we were interested in investigating if they generally tend to take risks. We believe that this tendency affects all people during decision making in uncertain conditions.

Our study showed that physicians do not have a general tendency to take risks; the mean gamble score was 5.5 (on a scale of $0-10$ ). Nevertheless, we found that senior doctors tend to gamble less than physicians with less experience. One might expect that experienced physicians rely more on experience than on facts in their decision making, rendering them greater risk takers. However, our study showed seniority to be a good predictor of low tendency to gamble/risk taking $(P<0.001)$.

Risk-taking scores were higher for surgeons and anesthesiologists than for physicians of other disciplines. We speculate that the quest for short-term results and the need for intervention to achieve results might be related to risk taking. In internal medicine, pediatrics and other disciplines, gathering information in order to confirm a certain diagnosis might involve a quest to resolve uncertainty and to avoid risk taking. We note that a small study identified a "surgical personality" among surgical residents, characterized by higher scores on the personality traits: extraversion, openness, and conscientiousness, as compared with the general population. Risk taking, however, was not assessed. ${ }^{4}$

In a study based on questionnaires, surgeons were less risk averse than other physicians and men were more prone to risk taking than women. ${ }^{5}$ Our results support these findings.

We found that female doctors tended to take less risk than male doctors. This tendency was not statistically significant, probably due to the relatively small sample of 26 female and 36 male physicians.
The tendency to gamble is probably affected by many factors such as socioeconomic status, education, and environmental influences. ${ }^{6}$ An association between risk taking and medical specialization could be due to an effect of work experience on the physician. Alternatively, risk-taking tendency may affect the selection of medical discipline.

Our study simplified a gambling situation, which differs from actual decision-making situations in medicine. Actual decision-making situations are obviously more complicated and probably, in uncertain conditions, based largely on previous experience rather than on risk taking. Nevertheless, though no game can precisely mimic real-life medical decisions, elucidation of the decision-making process and the factors that affect it may contribute to understanding causes of adverse events and to the education of physicians. For example, a study that assessed risk taking according to a questionnaire found that physicians who were risk avoiding tended to rely more on evidence-based data, such as provided by Cochrane reviews and Up-to-date systematic reviews, compared with physicians who were characterized as risk seekers. ${ }^{7}$

Decision making in medicine might sometimes be under pressure of time or circumstances and therefore require fast thinking and even risk taking. Game theory might help us in simulating decision making in various situations and as such to be an investigative as well as an educational tool. Other games might be even more accurate and help in isolating certain behaviors or situations.

Previous works have shown that the tendency to gamble might be genetic or related to behavioral or even neurophysiological disorders. ${ }^{8-10}$ We do not suggest that doctors have such disorders. On the contrary, our work showed that physicians in general do not tend to gamble; the average of the scores was close to the middle. On the other hand, the distribution of scores was across the entire scale, from low to high risk. 
Our study is the first, to the best of our knowledge, to use game theory to understand decision making among physicians. Other aspects of decision making, other than risk taking, might be studied using game theory and serve as a possible education tool.

\section{Conclusion}

Using game theory to examine doctors' tendency to gamble showed that surgeons and anesthesiologists tended to gamble more, while senior doctors tended to gamble less. Female physicians also tended to be less risk taking than male doctors, though this finding was not statistically significant. Further studies on this subject may elucidate factors influencing decision making in medicine, serve as an educating tool, improve our professionalism, and lessen adverse events.

\section{Disclosure}

The authors report no conflicts of interest in this work.

\section{References}

1. Myerson, Roger B. On the value of game theory in social science. Ration Soc. 1992;4(1):62-73.

2. Schwalbe U, Walker P. Zermelo and the early history of game theory. Game Econ Behav. 2001;34(1):123-137.

3. Pauker SG, Kassirer JP. The threshold approach to clinical decision making. N Engl J Med. 1980;302:1109-1117.

4. McGreevy J, Wiebe D. A preliminary measurement of the surgical personality. Am J Surg. 2002;184(2):121-125.

5. Garagan IJ, Conneely JB, Burke M, Kerin MJ. The personality traits of surgeons: assessment of risk-taking predisposition among consultant and trainee surgeons. J Am Coll Surg. 2008;207(3):S95.

6. Blume SB. Pathological gambling. BMJ. 1995;311(7004):522-523.

7. McKibbon KA, Fridsma DB, Crowley RS. How primary care physicians' attitudes toward risk and uncertainty affect their use of electronic information resources. J Med Libr Assoc. 2007;95(2):138-146, e49-e50.

8. Griffiths M. Pathological gambling and treatment. Br J Clin Psychol. 1996;35(3):477-479.

9. Thomas NJ. Examination of Addiction and Level of Engagement in Potentially Addictive Activities: Gambling, Video-arcade Games, Computer Games and the Internet. $\mathrm{PhD}$ thesis, Library Open Repository, 2007. Chapter 4.

10. Redish AD, Jensen S, Johnson A, Kurth-Nelson Z. Reconciling reinforcement learning models with behavioral extinction and renewal implications for addiction, relapse, and problem gambling. Psychol Rev. 2007;114(3):784-805.
Risk Management and Healthcare Policy

\section{Publish your work in this journal}

Risk Management and Healthcare Policy is an international, peerreviewed, open access journal focusing on all aspects of public health, policy, and preventative measures to promote good health and improve morbidity and mortality in the population. The journal welcomes submitted papers covering original research, basic science, clinical \& epidemio-

\section{Dovepress}

logical studies, reviews and evaluations, guidelines, expert opinion and commentary, case reports and extended reports. The manuscript management system is completely online and includes a very quick and fair peerreview system, which is all easy to use. Visit http://www.dovepress.com/ testimonials.php to read real quotes from published authors. 